\title{
Modos de negar em Wapichana
}

\author{
Ways of negation in Wapichana
}

\section{Renato Miguel Basso Marcelo Giovannetti}

RESUMO: A negação é uma característica básica de toda língua natural, e sua compreensão é fundamental para lidarmos com sentenças falsas ou contraditórias, resultantes da aplicação do operador de negação a uma sentença. Em semântica e pragmática formal, estudar a negação é também interessante por destacar sua interação com outros operadores como quantificadores e modalizadores. Neste artigo, analisaremos a negação em Wapichana, uma língua indígena brasileira, da família Arawak, falada em Roraima, na Venezuela e na Guiana, tomando como aporte teórico a Semântica Formal. Dividimos este artigo do seguinte modo: na primeira seção, faremos uma tipologia mínima sobre a negação nas línguas naturais; na sequência, caracterizaremos a língua Wapichana entre as línguas naturais, discutindo questões relacionadas à sua tipologia. Na seção 3, passaremos à discussão sobre a negação nessa língua, abordando, nas subseções de 3.1 a 3.4, alguns de seus diferentes aspectos, quais sejam, a diferença entre as negações realizadas por "auna'a" e "auna'a naa"; a especificidade da forma "manaa" para a realização da negação no imperativo; o prefixo "may-", como uma forma presa responsável pela negação de certos substantivos e adjetivos; e, por fim, uma discussão sobre a contribuição da forma "naa" no que chamamos de "negação pressuposicional".

Palavras-chave: negação, pressuposição, Wapichana, semântica, pragmática

ABSTRACT: Negation is a basic and intrinsic feature of all natural language, that is crucial to explain a variety of phenomena such as false sentences, contradictions and interaction with other operators. In Formal Semantic and Pragmatic, the interaction between negation and other operators, such as quantifiers and modals, and presupposition plays an important role. In this paper, using the tools of Formal Semantics, we analyze the phenomenon of negation in Wapichana, an Arawak indigenous language, spoken in Roraima, Brazil, in Venezuela and in Guyana. This paper is organized as follows: in the first section we will take a minimum typology of negation phenomenon in natural languages; in the following section, we will characterize the Wapichana language among natural languages, discussing issues related to its typology. In section 3, we discuss the phenomenon of negation in that language, addressing, in subsections 3.1 to 3.4, different aspects related to the negation, such as the differences between the forms "auna'a" and "auna'a naa"; the specificity of the form "manaa" for the expression of negation in the imperative; the prefix "may-" as a suffix responsible for the negation associated with certain nouns and adjectives. Finally, we discuss the contribution of the morpheme "naa" in what we call "presuppositional negation."

Keywords: Negation, Presupposition, Wapichana, Semantics, Pragmatics 


\section{Introdução}

Uma característica básica das línguas naturais é a negação: todas as línguas naturais têm algum modo de representar o significado oposto de valor de verdade de sentenças assertivas. Desse modo, não seria um equívoco afirmar que a negação é algo intrínseco à linguagem humana (cf. Deustcher, 2014, cap. 7).

Compreender a negação nos auxilia a lidar com sentenças falsas ou contraditórias, uma vez que essas são definidas por possuírem seu valor de verdade alterado com relação à sua contraparte sem negação, justamente pela presença do operador de negação. Mais do que isso, para a Semântica e a Pragmática Formal das línguas naturais, investigar a negação tem uma relevância especial na medida em que ela possui uma interação complexa e sistemática com outros operadores da língua, como termos quantificacionais e modais.

Contudo, a complexidade da negação nas línguas naturais não se esgota em suas interações. Em língua natural, podemos falar, pelo menos, em negação sentencial, negação de constituinte, negação com prefixos, negação pressuposicional, negação escalar, negação metalinguística, etc. Essas possibilidades ilustram a intrincada relação que a interpretação da negação tem com sua realização linguística, que se dá em um jogo interessante entre sintaxe, morfologia, léxico e, muitas vezes, entoações específicas.

Neste artigo, nosso objetivo é apresentar e investigar algumas das possibilidades de negação em Wapichana falado em território brasileiro, da família Arawak. Como veremos neste texto, a negação em Wapichana apresenta certas peculiaridades que podem ser capturadas por meio de testes linguísticos.

Sendo assim, o presente texto se organiza da seguinte forma: na seção 1, apresentaremos alguns fatos sobre negação e sua tipologia linguística; na seção 2, apresentaremos a língua Wapichana em suas características gerais, para, na seção 3, investigarmos alguns dos modos de negar nessa língua. Finalmente, na Conclusão, apresentaremos um resumo do percurso feito e as conclusões a que chegamos.

\section{Negar em língua natural - tipologia mínima}

Nesta seção, falaremos um pouco sobre as várias maneiras de negar em língua natural. Além da negação sentencial, há aquelas que envolvem o fenômeno chamado de negação de constituinte, ou negação nuclear (MIOTO, 1998). Essa breve exposição, que está longe de esgotar as possibilidades de negar em PB, traz algumas maneiras de negar nas línguas naturais, sua grande diversidade e algumas nuances semânticas associadas à negação.

Enquanto na negação sentencial o escopo da negação é toda a sentença, na negação de constituinte, como o próprio nome indica, a negação tem escopo sob um único constituinte, como exemplificado em (1) e (2):

(1) João é um falante não-nativo de inglês. 
(2) As pesquisas com fluidos não-newtonianos ajudaram a compreender os tipos de materiais.

Nesse tipo de estrutura, por exemplo, a negação incide apenas no NP negado, haja vista que possíveis paráfrases para (1) e (2) poderiam ser:

(3) João é um falante de inglês que não é nativo.

(4) As pesquisas com fluidos que não são newtonianos ajudaram a compreender os tipos de materiais.

Além dos casos de negação sentencial e de constituinte, a negação aparece também em forma de pergunta eco. Segundo Ilari e Basso (2014, p. 315), “Uma pergunta em eco pode ser afirmativa ou negativa, e uma pergunta em eco negativa é sempre verbalizada quando se espera uma resposta afirmativa (...)", como se observa em:

(5) a menina toma conta - precocemente...não? - das atividades dos irmãos [D2POA 291] (ILARI; BASSO, op. cit.)

A sentença (5) poderia ser parafraseada por

(5') a menina toma conta - precocemente...não é mesmo?

A negação com o "não" aparece tipicamente como resposta a "perguntas polares", cujo objetivo é propor um conteúdo proposicional completo ao interlocutor, deixando-o a tarefa de escolher entre uma resposta afirmativa ou negativa, como exemplificado abaixo:

(6) A: Você gosta de sorvete?

B: Não

Se B tivesse respondido sim, ele teria aceitado o conteúdo "Eu gosto de sorvete"; como sua resposta foi não, sua adesão se deu ao conteúdo "Eu não gosto de sorvete", que, em última instância, nega o conteúdo "Eu gosto de sorvete".

Uma outra forma de realização da negação em algumas línguas como o Português é a negação de um constituinte pelo acréscimo de um prefixo ao substantivo ou adjetivo, por exemplo, como vemos nos pares 'feliz/infeliz', 'perfeito/imperfeito', 'esperançoso/desesperançoso' e em palavras que não apresentam pares de oposição, tais como 'ateu' e 'acéfalo', entre outras.

A negação apresenta interessantes relações com predicados escalares, como os exemplos abaixo evidenciam:

(7) João não é feliz 
(8) João é infeliz

(9) João não é infeliz

(10) Nem o João veio.

Note que (7) não acarreta (8), ou seja, do fato que João não é feliz não podemos concluir que ele seja infeliz, como atesta a possibilidade de dizermos, sem contradição, uma sentença como (11):

(11) João não é feliz nem infeliz.

Do mesmo modo, (9) não acarreta que João é feliz (cf., 'João não é infeliz nem é feliz'). Uma explicação para essa configuração pode se pautar no fato de que "feliz" e "infeliz" caracterizam polos numa escala de "felicidade", e negar que alguém esteja num polo (como em (7) ou em (9)) não nos permite concluir que este alguém esteja automaticamente no polo oposto.

Finalmente, com (10) indicamos que quase ninguém veio para a festa se, afinal, nem o João veio. A ideia de escala é mobilizada aqui de modo a usar uma escala de "pessoas que provavelmente viriam à festa". Nessa escala, João é colocado como alguém que tem grande probabilidade de ir à festa, e dizemos que ele não foi. Ora, se alguém que tem grande probabilidade de ir à festa não foi, provavelmente pouca gente foi.

Ainda com relação a escalas, não podemos falar de negação sem tocar na questão dos itens de polaridade negativa, exemplificados pelas construções sublinhadas abaixo:

(12) João não levantou um dedo pra ajudar.

(13) ? João deu um pio na aula.

Trata-se de construções que são licenciadas sob o escopo de uma negação (mas não somente), e têm um significo de "frase feita" sob o escopo de uma negação, mas um significado composicional quando fora do escopo de uma negação; nesse último caso, com interpretação composicional, em geral, o resultado são sentenças estranhas, como (13).

Próximas a essas construções, encontramos alguns itens que relevam um tipo de "concordância negativa", sendo também somente licenciados quando há uma negação presente na sentença, como abaixo:

(14) Tem alguém em casa

(15) Não tem ninguém em casa 
(16) ? Tem ninguém em casa

Não é apenas o advérbio 'não' o responsável pela negação no PB; podemos ter, além dos prefixos, tais como 'in-', 'im-', 'i-', 'a-', entre outros, elementos como 'nunca', 'jamais', 'nem' e 'sem', por exemplo, além dos quantificadores com valor negativo como 'ninguém', 'nada', 'nenhum', responsáveis pela negação dentro do sintagma nominal, como mostram os exemplos a seguir (NEVES, 2000, pp. 290-1):

(17) Todo mundo foi embora e ninguém me disse adeus

(18) Nada para contar. Nada para acrescentar à queixa dos dias anteriores.

(19) Nenhum dos alunos da Escola de Polícia teve qualquer envolvimento com os fatos ocorridos.

Na próxima seção, discorreremos sobre algumas características da língua Wapichana e sua localização entre as línguas naturais, para então olharmos para aspectos da negação nessa língua na seção 3.

\section{Wapichana entre as línguas naturais}

A língua Wapichana é falada atualmente pelo povo homônimo, que habita parte do território da República Cooperativa da Guiana e a região da Serra da Lua, que contém os municípios de Cantá e Bonfim, em Roraima. Alguns integrantes das comunidades Wapichana próximas a Boa Vista frequentam cursos de formação superior no Instituto Insikiran de Formação Indígena, na Universidade Federal de Roraima. Essa língua é classificada como pertencente à família Arawak (RODRIGUES, 1986), embora haja duas classificações para a família a que pertence a língua Wapichana, segundo Santos (2006): uma, baseada em Greenberg (1956 apud SANTOS, 2006), que a coloca como pertencente à família Maipuran, subgrupo do tronco Arawakan, filiado ao supermacrotronco Equatorial; as propostas de Greenberg não são completamente aceitas pelos estudiosos da linguística histórica. A outra classificação, bem mais aceita, é a de Payne (1991 apud SANTOS, 2006), segundo a qual a língua Wapichana faz parte da família Maipuran, pertencente ao grupo Northern.

Quanto à morfologia, a língua Wapichana apresenta as categorias gramaticais tradicionalmente consideradas, como nome e verbo, além de adjetivos, advérbios, numerais, demonstrativos e pronomes. Contudo, ela não apresenta determinantes do tipo dos artigos, embora apresente numerais e pronomes indefinidos junto ao nome. Além disso, o Wapichana apresenta distinção de número e gênero, marcado em alguns nomes; a distinção entre singular e plural é feita pelo sufixo '-nau', descrito em Pires de Oliveira e Giovannetti (2016) como um coletivizador, enquanto a distinção entre masculino e feminino é realizada pelo sufixo '-maibe', descrito em Santos (2006). 
Seguindo a classificação tipológica de Greenberg (1966), o Wapichana é uma língua SVO. Contudo, ela apresenta algumas características de línguas SOV, tal como a presença de posposições ao invés de preposições. Essa situação, em princípio, põe em xeque o Universal 3 de Greenberg: "línguas com ordem normal SOV são posposicionais" (GREENBERG, 1963/1966, p.79), que é exemplificado pelo japonês e pelo sateré-mawé ${ }^{1}$. Em línguas SVO, os substantivos precederiam os adjetivos; comportamento também encontrado em Wapichana, que, além disso, apresenta concordância de gênero e número entre adjetivos e substantivos, como discutimos em Giovannetti (2015; 2016).

O Wapichana também apresenta algumas características peculiares no que se refere ao número de morfemas junto ao verbo para indicar tempo, modo e aspecto, de forma que essa língua se comporta de modo similar a uma língua polissintética, muito embora o fato de ela ser ou não polissintética é controverso.

É com essa rápida exposição sobre o Wapichana como pano de fundo que nos voltamos, a seguir, a uma exposição mais detalhada do comportamento de alguns modos de negação existentes nessa língua.

\section{Negação em Wapichana}

Na língua Wapichana, temos a princípio três modos distintos de negação, na medida em que são realizados por três itens diferentes, a saber, "auna'a”, "auna'a naa" e "manaa", além de um prefixo, 'may-'. Os exemplos abaixo ilustram esses itens:

(20) Auna'a unaichipan

Auna'a un- aichipa -n

NEG 1ps SABER MI ${ }^{2}$

"Eu não sei"

(21) Auna'a wamazidian nii

Auna'a wa- mazidia $-\mathrm{n}$ nii

NEG 1pp CASAR MI NPRES ${ }^{3}$

"Nós não vamos nos casar"

(22) Auna'a naa inmeaku'uzun pa kidib bauran dun

Auna'a naa in-meaku'u-zun ${ }^{4}$ pa kidib bauran dun

NEG ? $3 p p$ IR DES POSS pé outra vez

${ }^{1}$ Em Giovannetti (2015), discutimos o comportamento tipológico específico das posposições em Wapichana, sua classificação, e sua relação com o Universal 3 proposto por Greenberg.

2 "1ps" = primeira pessoa do singular, "Ml" = modo indicativo.

${ }^{3} \mathrm{O}$ morfema 'nii' é tradicionalmente tratado como marca de "não-presente" (NPRES), contudo, essa descrição ainda é incompleta e precisa ser mais bem elaborada.

${ }^{4} \mathrm{O}$ morfema "-zun" é desiderativo (DES). 
"Eles não quiseram mais ir a pé novamente"

(23) Manaa pyxa'aptaa naa wyry'y

Manaa py- xa'aptaa naa wyry'y

NEG 2ps FAZER ? isso

"Não faça isso"

(24) Daunaiura maydaiaruchi

Daunaiura may- daiaru- chi

homem PRIV. gênese ADJR ${ }^{5}$

"Homem que nunca teve esposa"

(SANTOS, 2006, p. 178)

(25) Kuxi maydanichi

Kuxi may- dani- chi

porco PRIV gênese ADJR

"Porco sem filho"

(SANTOS, op. cit.)

Neste trabalho, nosso interesse está nos itens 'auna'a' e 'auna'a naa', principalmente em suas peculiaridades semânticas, que trataremos na seção 3.1; na seção 3.2, abordaremos a forma 'manaa' (que aparece no imperativo), e na seção 3.3, o prefixo 'may-'.

\subsection{Negação com 'auna'a' e 'auna'a naa'}

Do ponto de vista sintático, os itens 'auna'a' e 'auna'a naa' ${ }^{6}$ parecem ocorrem sempre antes do verbo principal da sentença, mas do ponto de vista semântico apresentam importantes especificidades. Nossa principal hipótese quanto ao significado desses itens pode ser resumida da seguinte forma:

i) auna'a: negação simples (NegSi) $\rightarrow$ este item nega o evento (ou estado) veiculado por uma dada sentença no âmbito de um determinado tempo relevante de referência;

ii) auna'a naa: negação pressuposicional (NegPre) $\rightarrow$ este item nega a possibilidade de ocorrência futura do evento (ou estado) veiculado por uma dada sentença desde que seja o caso que pelo menos um evento do mesmo tempo tenha ocorrido pelo menos uma vez

\footnotetext{
${ }^{5}$ Adaptamos as glosas a partir de Santos (2009): PRIV - privativo; POSS - possuído; ADJR - adjetivizador; gênese - "ser filho de". O morfema "naa" será discutido na seção 3.4; contudo, podemos adiantar que não está clara ain da se temos um caso de homonímia ou não entre os "naa" presentes nas sentenças em (23) e (24).

${ }^{6}$ Como é possível ver no exemplo em (23) e em outros mais a frente, a forma 'naa' pode aparecer em outras posições sintáticas. A forma que nos interessa é aquela que aparece sempre depois de uma negação. Na seção 3.4, voltaremos a essa forma.
} 
antes.

Em PB, podemos ilustrar a diferença entre esses dois tipos de negação com os exemplos abaixo:

(26) a) No meu quintal não dá mamão

b) No meu quintal não dá mais mamão

Com (26a), não sabemos se o quintal do falante já produziu mamão antes, mas apenas que, para os propósitos do período de tempo relevante para a conversação, não é o caso que o quintal dê mamão, podendo inclusive ser o caso que o quintal nunca tenha dado mamão e que nunca venha a dar. Por sua vez, (26b) indica que o quintal do falante já deu mamão antes, mas que não dá mais no presente e (provavelmente) não dará mais no futuro ${ }^{7}$. É justamente pela necessidade de haver a ocorrência prévia de um evento do mesmo tipo daquele negado na sentença que podemos chamar a negação em (26b) de "negação pressuposicional". Se fizermos o teste da P-família, temos que:

(26c) No meu quintal não dá mais mamão?

(26d) Se no meu quintal não dá mamão, então vou comprar mamão.

Observamos, assim, que tanto (26b) quanto (26c) e (26d) têm como pressuposto algo como "No meu quintal dava/deu mamão (antes)", conteúdo que não é garantido na negação realizada em (26a) - mais uma vez, é essa a intuição que está por trás da nossa distinção entre "negação simples" vs. "negação pressuposicional".

No que segue, apresentaremos alguns argumentos a favor de tal análise para os itens do Wapichana, como:

(a) a não combinação de 'auna'a naa' com advérbios como 'nunca';

(b) a relação desses itens com advérbios de interpretação pontual como 'agora';

(c) a combinação com sentença que trazem eventos sempre verdadeiros (falsos);

(d) o teste da família pressuposicional (p-família).

\footnotetext{
${ }^{7}$ A qualificação "provavelmente" aqui indica que não vamos nos comprometer com (26b) acarretar uma impossibilidade de (re)ocorrência futura, mas meramente implicando essa impossibilidade. Assim, uma sentença como "No meu quintal não dá mais mamão, só depois de adubar tudo novamente" não é contraditória. Por sua vez, uma sentença como ? "No meu quintal não dá nunca mais mamão, só depois de um adubar tudo novamente" é estranha. Abaixo, veremos uma pouco mais sobre o 'não... mais' e o '(não...) nunca mais'. Vale notar, contudo, que em Wapichana a impossibilidade de ocorrência futura é acarretada com 'auna'a naa', fazendo com que essa negação se assemelha mais ao '(não...) nunca mais' do PB.
} 
(a) a não combinação de 'auna'a naa' com advérbios como 'nunca'

Acima, apresentamos alguns tipos de negação em Wapichana ('auna'a', 'auna'a naa', 'manaa' e o prefixo 'may-'), mas essas formas não esgotam as possibilidades de negar nessa língua. Uma outra forma de negação que nos interessa é aquela na qual aparece o equivalente ao PB 'nunca', como podemos ver ao contrastar os exemplos abaixo:

(27) Auna'a naa Pedro tykap kuazaze

Neg ? 3ps VER cobra

"Pedro não vê mais cobra"

(28) Auna'a Pedro tykap kuazaze

Neg 3ps VER cobra

"Pedro não vê cobra"

(29) Auna'a Pedro tykapizun kuazaze

Auna'a Pedro tykap -izun kuazaze

Neg 3 ps VER nunca cobra

"Pedro nunca vê cobra"

O exemplo em (29) nos mostra que o significado comumente atribuído ao 'nunca' do PB é expresso em Wapichana por uma negação, 'auna'a', e um sufixo verbal, '-izun'.

É interessante notar que o item negativo necessário para a presença de '-izun', que o licencia, é a negação simples, 'auna'a', e não a negação pressuposicional, 'auna'a naa'. Isso está de acordo com nossa hipótese, pois de fato não devemos esperar que 'nunca' se combine com estruturas que pressupõem a existência anterior de um evento do mesmo tipo, uma vez que ele cancela a pressuposição de que tal evento tenha ocorrido; assim, temos a agramaticalidade abaixo:

(30) *Auna'a naa Pedro tykapizun kuazaze

Auna'a naa Pedro tykap -izun kuzaze

Neg ? 3ps VER nunca cobra

"Pedro não vê mais cobra nunca"

O mesmo pode ser visto em PB:

(31) João não vê mais cobra.

(32) ? João não vê mais cobra nunca.

(33) ? Nunca João vê mais cobra. 
No entanto, algumas sentenças com 'nunca' e '(não...) mais' em PB são aceitáveis:

(34) Nunca mais João vê cobra.

(35) João não vê nunca mais cobra.

Note, contudo, que nesses casos não temos uma negação pressuposicional mais o 'nunca', mas sim uma negação pressuposicional da qual o 'nunca' faz parte, ou seja, temos algo como 'nunca mais' que indica que há um ponto (no tempo) a partir do qual eventos do tipo descrito (i.e., ver cobra) não mais acontecem. Desse modo, 'nunca mais' tem um significado muito próximo de 'não... mais':

(31) João não vê mais cobra.

(34) Nunca mais João vê cobra.

(35) João não vê nunca mais cobra.

A contribuição de 'nunca' em (34) e (35), acima, numa primeira análise, pode chamar a atenção de forma mais saliente que (31) para o momento a partir do qual João passou a não ver mais cobras, mas garante a ocorrência de pelo menos um evento prévio de ver cobra. A diferença entre (31), por um lado, e (34) e (35), por outro, pode estar no fato de que, com as últimas sentenças, indicamos que, no futuro, João não verá cobra, ao passo que (31) nada diz sobre eventos futuros.

Seja como for, se separarmos 'nunca mais' teremos uma NegPre e 'nunca', gerando uma sentença ruim porque a NegPre requer a ocorrência de um dado evento e 'nunca' veicula que esse evento não teve ocorrência nenhuma (a não ser, como notamos, quanto temos 'nunca mais').

Os outros exemplos do Wapichana, abaixo, mostram a incompatibilidade da NegPre dessa língua com o sufixo verbal que indica 'nunca'.

(36) *Puaty auna'a naa pidianizun ${ }^{8}$

Puaty auna'a naa pidian -izun

Macaco NEG ? gente nunca

"Macaco não é mais gente nunca"

${ }^{8}$ A língua Wapichana é caracterizada por não apresentar o fenômeno da cópula; contudo, podemos observar pela posição sintagmática do 'auna'a naa' que ele toma como escopo, em sentenças que seriam tidas como copulares, o predicado. O fenômeno da ausência da cópula em Wapichana ainda requer mais estudos. 
(37) *Wyn auna'a naa zabiayizun

Wyn auna'a naa zabiay -izun

Água NEG ? MOLHAR nunca

"Água não molha mais nunca"

Temos assim nossa primeira evidência de que 'auna'a naa' é uma NegPre e 'auna'a' é uma NegSi.

(b) a relação desses itens com advérbios de interpretação pontual como 'agora'

Em princípio, podíamos esperar que uma NegPre fosse compatível com advérbios pontuais e mesmo com sentenças episódicas que versem sobre momentos precisos do tempo. Esse é o caso do $\mathrm{PB}^{9}$ :

(38) João não come mais carne hoje.

(39) João não comeu mais carne hoje.

(40) João não come mais carne agora.

Contudo, isso só pode ser o caso se a NegPre não disser nada sobre a possibilidade futura de ocorrência do evento em questão para além do limite temporal considerado. Mas tanto a NegPre do Wapichana quanto a NegPre com 'nunca' do PB ('nunca mais') versam sobre o futuro de modo que são incompatíveis com advérbios temporais pontuais:

(44) ? Nunca mais o João come carne hoje.

(45) ? Nunca mais o João come carne agora.

(46) ? João não come carne nunca mais hoje.

(47) ? João não come carne nunca mais agora.

(note que essas sentenças só são marginalmente aceitáveis se 'hoje' e 'agora' forem interpretados como 'atualmente', 'nos últimos dias', 'atualmente', etc., e não como advérbios pontuais de fato).

Em Wapichana, temos o advérbio 'kai' ('agora'), que é preferencialmente interpretado como pontual, e por isso as sentenças abaixo não são aceitáveis com a NegPre 'au-

\footnotetext{
${ }^{9}$ Em princípio, devemos considerar os advérbios 'hoje' e 'agora' nos exemplos como pontuais, e não como equivalentes a algo como 'atualmente'.
} 
na'a naa', mas - é importante notar - são todas compatíveis se tivermos a NegSi 'auna'a' no lugar da NegPre; comparem-se as sentenças abaixo:

(48) * Auna'a naa ma'apai nii zakap ii kai. Neg ? mamão NPRES roça em agora

"Não tem mais mamão na roça agora"

(48') Auna'a ma'apai nii zakap ii kai

Neg mamão NPRES roça em agora

"Não tem mamão na roça agora"

(49) * Auna'a naa wyn da'aa kai

Neg ? água aqui agora

"Não tem mais água aqui agora"

(49') Auna'a wyn da'aa kai

Neg água aqui agora

"Não tem água aqui agora"

(50) * Auna'a naa pidian nii da'aa kai

Neg ? pessoa NPRES aqui agora

"Não tem mais ninguém aqui agora"10

(50') Auna'a pidian nii da'aa kai

Neg pessoa NPRES aqui agora

"Não tem ninguém aqui agora"

(51) *Auna'a naa Pedro tykap kuazaze kai

Neg ? ver cobra agora

"Pedro não vê cobra agora"

(51') Auna'a Pedro tykap kuazaze kai

Neg ver cobra agora

"Pedro não vê cobra agora"

Vemos que com a presença de um advérbio pontual, o uso da forma 'auna'a naa' é barrado, uma vez que a ideia de algo que subsiste impõe que haja um tempo decorrido, que não seja apenas algo pontual. Esse é o segundo argumento que apresentamos em fa-

${ }^{10}$ É importante atentar para o fato de que o 'mais' se combina com o 'não', e não com 'ninguém'; a intepretação seria algo como já houve pessoas aqui, mas não há mais (ignorando o advérbio temporal). 
vor da hipótese que avançamos aqui. Vejamos o próximo argumento.

(c) a combinação com sentença que trazem eventos sempre falsos (verdadeiros)

Consideremos as sentenças em Wapichana, abaixo:

(52) Puaty auna'a pidian

macaco Neg pessoa

"Macaco não é gente"

(53) * Puaty auna'a naa pidian

macaco NEG ? pessoa

"Macaco não é mais gente"

Nesse caso, vemos que somente a NegSi 'auna'a' é aceitável, e a explicação para tanto pode ser encontrada na definição de NegPre que demos acima: não há a ocorrência prévia do evento (no caso, estado) que está sob o escopo da negação. Em outras palavras, como macaco nunca/jamais foi gente/pessoa, não podemos usar a NegPre 'auna'a naa' porque ela exige a ocorrência prévia do que está sendo negado, o que não se verifica para o caso em questão.

Temos algo parecido em PB:

(54) ? Macaco não é (nunca) mais gente.

Mas podemos ter, por outro lado, a forma com 'nunca' em ambas as línguas:

(55) Macaco nunca é/foi gente

(56) Puaty auna'a pidianizun

Puaty auna'a piian -izun

macaco NEG gente nunca

"Macaco nunca é gente"

Note que o que acontece é que a sentença de base, por assim dizer, que é 'Macaco é gente' é falsa (e sempre falsa), por isso não há nenhuma ocorrência do estado que licencia uma NegPre. Mas o que acontece quando temos uma sentença de base que é sempre verdadeira?

Vamos usar a sentença abaixo:

(57) Macaco come banana 
(58) Puaty nyken syyz

macaco comer banana

"Macaco come"

Para todos os efeitos, essa sentença é verdadeira e sempre o foi. Vejamos as possibilidades de negação com NegSi e NegPre:

(59) Macaco não come banana.

(60) Auna'a puaty nyken syyz

NEG macaco comer banana

"Macaco não come"

(61) ? Macaco não come mais banana.

(62) * Auna'a naa puaty nyken syyz

NEG ? macaco comer banana

"Macaco não come mais banana"

Como podemos ver, somente as sentenças com a NegSi, em (59) e (60), são boa nas duas línguas. A NegPre não é, e a causa de sua estranheza (ou agramaticalidade) é as sentenças resultantes irem contra os fatos do mundo que conhecemos. Em Wapichana, os julgamentos de estranheza (ou agramaticalidade) são ainda mais fortes. Ou seja, argumentamos que à diferença das sentenças sempre falsas, que eram ruins porque havia uma faIha de pressuposição, nos casos de sentenças sempre verdadeiras, elas são ruins porque expressam, no caso dos exemplos analisados, uma generalização que sabemos ser (sempre) falsa.

Os argumentos que trouxemos até agora mostram com bastante força que 'auna'a naa' é o que chamamos de NegPre e 'auna'a' de NegSi. Mas, se é esse de fato o caso, é preciso fazer o teste da p-família para 'auna'a naa'; esse o tópico da próxima seção.

\section{(d) o teste da família pressuposicional (p-família)}

O teste da p-família, ou família pressuposicional, nos garante que "Para uma sentença A, chamamos de P-família (ou seja, 'família pressuposicional') [...] um conjunto que inclui $A$, a sua negação, a interrogação de A e o condicional formado com A." (Chierchia, 2003, 186). Dessa forma, temos: 
se $A$ pressupõe $B$, então:

a negação de $A$ pressupõe $B$;

a interrogação de $A$ pressupõe $B$;

a condicional formada com A pressupõe B.

Vamos exemplificar isso com o exemplo a seguir, que traz o verbo 'parar' - um "gatilho pressuposicional":

(63) João parou de fumar

pressupõe

(64) João fumava/fumou antes

a negação de (63) pressupõe (64)

Não é verdade que João parou de fumar / João não parou de fumar

a interrogação de (63) pressupõe (64)

João parou de fumar?

a hipótese (condicional) de (63) pressupõe (64)

Se João parou de fumar, a Maria está feliz.

Observamos que tanto a negação quanto a interrogação e o condicional mantêm a pressuposição de que "João fumava/fumou antes". O mesmo teste pode ser aplicado na língua Wapichana a fim de corroborar nossa hipótese de que a negação feita com 'auna'a naa' é pressuposicional, diferentemente do que ocorre com 'auna'a', como observamos nos exemplos abaixo, primeiramente com dados do PB:

(65) No meu quintal não dá mais mamão

pressupõe

(66) No meu quintal já deu mamão

a negação de (65) pressupõe (66)

Não é verdade que no meu quintal não dá mais mamão

a interrogação de (65) pressupõe (66)

No meu quintal não dá mais mamão?

a hipótese (condicional) de (65) pressupõe (66)

Se no meu quintal não dá mais mamão, a Maria está feliz.

Nenhuma dessas pressuposições é encontrada com a sentença: 
(67) No meu quintal não dá mamão.

Olhando agora para os dados do Wapichana, temos:

(68) Ungary panibezut dia'a auna'a ma'apai kakan

1ps terreiro posp NEG mamão $\mathrm{CF}^{11}$

"No meu quintal não dá mamão"

(69) Ungary panibezut dia'a auna'a naa ma'apai kakan

$1 p s$ terreiro posp NEG ? mamão CF

"No meu quintal não dá mais mamão"

A negação em (68) não nos permite concluir nada sobre o evento de "dar mamão" em algum momento anterior à fala nem em momento posterior a ela, embora possamos ter uma leitura genérica da sentença. Por sua vez, na sentença em (69), a forma 'auna'a naa', como prevemos, funciona como um "gatilho pressuposicional", ativando a pressuposição de que antes do momento de fala, dava mamão no meu quintal, e dizendo que o quintal não dará mais mamão no futuro. Vejamos o teste da P-família para (69):

(69) Ungary panibezut dia'a auna'a naa ma'apai kakan

pressupõe

(70) Ungary panibezut dia'a ma'apai kakayz

$1 p s$ terreiro posp. mamão CF

"No meu quintal, dava mamão"

a negação de (69) pressupõe (70)

Auna'a mixi'u man ungary panibezut dia'a auna'a naa ma'apai kakan

NEG verdade mesmo 1ps terreiro posp. NEG ? mamão CF

Não é verdade que no meu quintal não dá mais mamão

a interrogação de (69) pressupõe (70)

Ungary panibezut dia'a auna'a naa ma'apai kakan?

1 ps terreiro posp. NEG ? mamão CF

"No meu quintal não dá mais mamão?"

a hipótese (condicional) de (69) pressupõe (70)

Ungary panibezut dia'a auna'a naa ma'apai kakaan unturian ma'apai

Ungary panibezyt dia'a auna'a naa ma'apai kakan un-turia- -n ma'apai $1 p$ terreiro posp. NEG ? mamão CF 1ps COMPRAR MI mamão

\footnotetext{
${ }^{11}$ A palavra 'kakan' remete ao fato de uma árvore frutífera estar cheia ou carregada de frutas, e por isso optamos por abreviar a glosa para CF, mnemônico para "carregado de frutas".
} 
"Se no meu quintal não dá mamão, então vou comprar mamão"

Após essa discussão sobre negação pressuposicional e negação simples, envolvendo 'auna'a naa' e 'auna'a', passaremos a uma breve discussão sobre o comportamento de outras duas formas de negar em Wapichana: a negação com 'manaa' e o prefixo 'may-'.

\subsection{A forma 'manaa' e a negação no imperativo}

A principal diferença detectada entre 'auna'a' e 'manaa' está no fato de 'manaa' ocorrer exclusivamente em formas imperativas, tanto com NegSi, exemplos em (a), quanto com NegPre, exemplos em (b):

(71a) Manaa pyxa'aptaa naa wyry'y

NEG 2ps FAZER ? isso

"Não faça isso"

(71b) Manaa naa pyxa'aptaa naa wyry'y

NEG ? 2ps FAZER ? isso

"Não faça mais isso"

(72a) Manaa pytizan naa wyry'y

NEG 2ps BEBER ? isso

"Não beba isso"

(72b) Manaa naa pytizan naa wyry'y

NEG ? 2ps BEBER ? isso

"Não beba mais isso"

(73a) * Manaa pyaichan naa wyry'y

NEG 2ps SABER ? isso

"Não saiba isso"

(73b) * Manaa naa pyaichan naa wyry'y

NEG ? 2ps SABER ? isso

"Não saiba mais isso"

Como é de esperar, verbos não-agentivos não funcionam no imperativo, o que explicaria a inaceitabilidade de (73), e a aceitabilidade de (74) e (75) abaixo, que são exemplos, respectivamente, da mesma sentença, agora em sua forma declarativa, com negação simples e pressuposicional: 
(74) Auna'a pyaichan naa wyry'y NEG 2ps SABER ? isso

"Você não sabe isso"

(75) Auna'a naa pyaichan naa wyry'y

NEG 2ps SABER ? isso

"Você não sabe mais isso"

Em nossas elicitações a forma 'manaa' teve muito baixa ocorrência, e apresenta alternância com 'auna'a', ou seja, 'auna'a' também pode aparecer em formas imperativas, apesar de 'manaa' ser preferida nesses casos em nossas elicitações e ser exclusiva de imperativos:

(76) Auna'a pyxa'aptaa naa wyry'y

NEG 2ps FAZER ? isso

"Não faça isso"

A forma 'manaa' precisa ser investigada mais a fundo; podemos, contudo, afirmar que, segundo os dados de nossa pesquisa, tal forma é de fato especializada para a negação no imperativo. Passemos, na sequência, à forma 'may-'.

\subsection{A forma 'may-'}

O prefixo 'may-' pode ser exemplificado pelas formas abaixo (repetimos alguns exemplos com a numeração atualizada):

(77) Daunaiura maydaiaruchi

Daunaiura may- daiaru -chi

homem PRIV. gênese ADJR

"Homem que nunca teve esposa"

(SANTOS, 2006, p. 178)

(78) Kuxi maydanichi

Kuxi may- dani -chi

porco PRIV gênese ADJR

"Porco sem filho"

(SANTOS, op. cit.)

(79) Pazaru maydaku'u

Pazaru may- daku'u

minhoca PRIV dente

"A minhoca é sem dente" 
(80) Ungary maydaniwei

Ungary may- dani -wei

1 ps PRIV gênese ?

"Eu sou órfão"

Pelas sentenças em (77) e (78), observamos que o prefixo 'may-' ${ }^{12}$ resulta numa interpretação que pode ser parafraseada por "desprovido de ..."; assim:

maydaiaruchi $=$ desprovido de esposa

maydanichi $=$ desprovido de filho

maydaku'u = desprovido de dente

maydaniwei $=$ desprovido de pais

Note ainda que nos casos de 'maydaiaruchi', 'maydanichi' e 'maydaku'u', o prefixo 'may-' se combina com adjetivos derivados dos nomes 'daiaru' ("esposa") e 'dani' ("filho", "prole"), a partir do sufixo adjetivador '-chi', e a partir do nome 'daku' ("dente") mais o sufixo adjetivador '-'u' . A derivação se dá da seguinte forma:

$\begin{array}{lll}\text { Nome } & \text { Adjetivador '-chi' } & \text { Prefixo 'may-' } \\ \text { daiaru } & \text { daiaruchi } & \text { maydaiaruchi } \\ \text { dani } & \text { danichi } & \text { maydanichi } \\ \text { daku } & \text { daku'u } & \text { maydaku'u }\end{array}$

Nosso estudo sobre tal forma ainda precisa, obviamente, ser mais aprofundado, mas serve para aumentar nosso panorama sobre a negação em Wapichana. A seguir, discorremos um pouco sobre a forma 'naa'.

\subsection{Sobre a forma 'naa'}

Santos (2009, p. 161-2), ao descrever o sistema verbal do Wapichana, afirma que essa língua recorre a apenas dois morfemas para realizar a marcação modo-temporal, quais sejam, o morfema ' $-\mathrm{n}$ ', indicador do modo indicativo, e o morfema 'nii', que, em conjunto com aquele morfema, determina as principais subcategorias verbais, como o

\footnotetext{
${ }^{12}$ Como pudemos ver, o prefixo "may-" combina-se exclusivamente com adjetivos e expressa o significado "ser desprovido de", chamado por Santos (2006) de "privativo". Advogamos para o fato de o morfema em questão é 'may-', não 'ma-', uma vez que os radicais aos quais ele é afixado são, respectivamente, 'daiaruchi' ("casado"), 'danii' ("ovo") e 'dakui' ("dente"); em 'daniwei', podemos observar o mesmo radical 'danii' ("ovo"), acrescido do sufixo 'wei'. Ademais, o mesmo morfema se repete em outras construções que indicam "falta de" ou "ausência", como, por exemplo, em 'maydaiary'u' ("solteira"), formada a partir do substantivo 'daiary' ("esposo"). Fazendo-se os pares mínimos, podemos argumentar que o prefixo é, realmente, 'may-', não 'ma-'. A descrição do sufixo 'wei' ainda não foi realizada de modo satisfatório, e terá que ser tema de trabalhos futuros.
} 
modo imperativo e os tempos presente, passado e futuro. Junto a essa descrição, Santos (op. cit.) afirma que "Subdivisões (...) parece ocorrer transversalmente mediante a combinação do morfema '-na:', indicador de que o evento expresso pelo verbo realizou-se, realizar-se-á imediatamente, ou já está se realizando (...)" (grifo nosso). De modo a corroborar sua explicação, o autor traz os seguintes exemplos, Santos (op. cit.):

(81) Auna'a piti'ida naa

Auna'a pi ti'id- -a naa

Neg 2ps ESTICAR EP IMM ${ }^{13}$

"Não estica"

(82) Itizipan naa

\section{I tizip a $n$ naa}

3ps BEBER EP MI IMM

"Ele já está bebendo"

(83) Itizinii naa

I tiz nii naa

3ps BEBER np IMM

"Ele já bebeu"

(84) Itizannii naa

I tiz a $n$ nii naa

3ps BEBER EP MI NPRES IMM

"Ele já vai beber"

Em (81), podemos ver a ocorrência da forma 'naa' com a negação simples, 'auna'a'; contudo, o que temos na negação pressuposicional é a forma 'auna'a naa', e o 'naa' que aparece de (81) a (84) não parece ser o mesmo item que investigamos neste trabalho. A descrição que Santos (2006) traz da forma 'naa' refere-se à sua justaposição ao verbo, de onde provêm os significados de perfectividade, futuridade e continuidade; em sua descrição sobre tal morfema, o autor (op. cit.) não diz nada sobre seu papel na negação.

A "Gramática Pedagógica do Wapichana" (no prelo), na unidade destinada à forma 'naa', traz a seguinte explicação:

O morfema "naa" - é usado quando quer informar algo que irá acontecer de imediato ou acontecido recentemente (acabou de acontecer). Assim:

O Paulo já matou aquele porco bravo.

Paulo zuia'anaa tawyry'y kuxi tu'urauraz. (passado recente/algo que ocorreu há pouco

\footnotetext{
${ }^{13}$ Temos a seguinte legenda: $\mathrm{MI}=$ modo indicativo; $\mathrm{EP}=$ epêntese; IMM = imediato; NPRES = não-presente.
} 
tempo.).

Pymakunnaa? Você já está indo? (algo que já está acontecendo/ próximo a acontecer.). Wyn kaawannaa. Já vai chover. (algo que já vai acontecer.).

Como é possível ver, a "Gramática Pedagógica do Wapichana" traz 'naa' como um morfema preso - ainda uma outra alternativa para entender o significado deste item. Seja como for, não nos parece razoável simplesmente supor nem que (i) haja três formas 'naa' diferentes em Wapichana, sem relação entre si, nem que (ii) a forma 'naa' seja algo como o 'mais' do português brasileiro (quando não está em função aditiva). Desse modo, ainda são necessários estudos mais aprofundados que possam empreender uma melhor descrição da forma 'naa', começando por uma definição clara de seu comportamento como forma livre ou presa e, até mesmo, sobre a possibilidade de estarmos lidando com homônimos.

O que podemos notar claramente é que precisamos de mais investigação sobre essa forma para poder entender seu papel em Wapichana.

\section{Conclusão}

No presente trabalho, buscamos compreender alguns dos diversos modos de negar encontrados na língua Wapichana. Para tanto, fizemos um percurso que se iniciou com uma breve tipologia sobre os modos de negar nas línguas naturais, em que tratamos dos aspectos morfológicos, sintáticos e semânticos da negação, procurando mostrar que as línguas apresentam várias formas de realizar a negação e nuances de significado decorrentes dessas diversas realizações. Em seguida, fez-se necessário apresentarmos uma tipologia mínima sobre a língua Wapichana, como modo de compreendermos alguns aspectos morfológicos e sintáticos referentes a ela, como a questão da ordem canônica e sua relação, por exemplo, com o fato de ela apresentar o fenômeno da posposição. Na seção 3, partimos, de fato, para o tratamento da negação em Wapichana, mostrando as diferenças existentes entre as formas 'auna'a' e 'auna'a naa', pelo fato de elas serem responsáveis pela negação que chamamos aqui de "simples" e "pressuposicional". Ainda na seção 3, procuramos descrever o funcionamento do prefixo 'may-' e da forma 'manaa'; para aquele, verificamos que seu comportamento é semelhante aos prefixos de negação em PB, com um significado de "desprovido de...". Em relação à forma 'manaa', nossos dados nos levaram a verificar sua alternância com a forma 'auna'a', o que nos faz hipotetizar sobre uma possível especialização do uso da forma 'manaa' em sentenças imperativas. Ao final, procedemos a uma rápida discussão do item 'naa', que precisa ser mais bem compreendido.

Com o presente texto, esperamos ter feito uma contribuição para o entendimento da negação em Wapichana, usando as ferramentas da Semântica e da Pragmática Formal das línguas naturais. Esperamos ainda que nossas distinções possam ser aprofundadas e usadas em outros trabalhos sobre essa língua, assim como esperamos que as questões levantadas por nós sejam futuramente exploradas. 


\section{Referências}

Aikhenvald, Alexandra Yurievna. (2012) Languages of the Amazon. Oxford University Press. . (1999) The Arawak language family. In: R. M. W. Dixon and A. Y. Aikhenvald (orgs.) The Amazonian Languages. Cambridge: Cambridge University Press. CARLSON, G. "A unified analysis of the English bare plural", in. Linguistics and Philosophy, 1, pp. 413-456, 1977. Brandão, Ana Paula. A reference grammar of Paresi-Haliti (Arawak). Texas: Univesrity of Texas at Austin, 2014 (Doctoral dissertation, Doctoral Dissertation).

Carlson, Gregory. (1977) "A unified analysis of the English bare plural", in. Linguistics and Philosophy, 1, pp. 413-456.

Choi, Jinyoung.(2007) Free choice and negative polarity - a compositional analysis of Korean polarity sensitive items. 358 pp, 2007. Tese de doutorado. Universidade da Pennsylvania.

de Swart, Henriette. (2009) Expression and interpretation of negation. An OT typology. In. http://www.let.uu.nl/ Henriette.deSwart/personal/Negot/negotbook.htm.

Deutscher, Guy. (2014) O desenrolar da linguagem. Campinas: Mercado de Letras.

Facundes, Sidi. (2000) The language of the Apurinã people of Brazil (Maipure/Arawak), (Doctoral dissertation, SUNY Buffalo).

Gamut, L.T.F.(1991) Logic, language, and meaning. Volume 1: Introduction to Logic. - The University of Chicago Press.

Gamut, L.T.F. (1991) Logic, language, and meaning. Volume 2: Intensional logic and Logic gramar. - The University of Chicago Press.

Giovannetti, Marcelo (2015) Posposições em Wapichana. Apresentação de trabalho.

(2016) "Notas sobre adjetivos em Wapichana: o caso da concordância de gênero" In. Maria do Socorro Pereira Leal; Leila Adriana Bataglin; Elder Lanes (orgs) Estudos de Linguagem e Cultura Regional: linguagem, sociedade e ensino, pp. 153-170. Boa Vista: Editora da UFRR.

Greenberg, Joseph Harold.(1963) Universals of Language. London: MIT Press, pp. 73-113. Guedes, Maria Leonor Gambini de Souza (1997) Semântica da negação prefixal. Coimbra, 1997. Dissertação de mestrado em Linguística Geral, apresentada à FLUC.

Horn, Laurence Robert. (1989) A natural history of negation. Chicago: University of Chicago Press.

Horn, Laurence Robert; Heinrich, W. Negation. The Stanford Encyclopedia of Philosophy (Summer 2015 Edition), Edward N. Zalta (ed.), URL = <http://plato.stanford.edu/archives/sum2015/entries/negation/>

Ilari, Rodolfo; Basso, Renato Miguel. Advérbios verificadores. In. ILARI, R.(Org.) (2014)

Gramática do Português Culto Falado no Brasil: volume III: palavras de classe aberta. - São Paulo: Contexto.

Juvêncio, Vítor .F.; Camilo, M. (s/d) Gramática Waparadan Day: sa'ad na'apdii waparadan. Michael, Lev David.(2014) Negation in Arawak Languages. UC Berkeley.

Michael, L. D. Negation in Arawak Languages. UC Berkeley, 2014. 
Mioto, Carlos. Tipos de negação. Caderno de Estudos Linguísticos, Campinas, vol. 34, pp: 103-117, Jan./Jun. 1998.

Mugarza, M.I.L. Negation in Syntax: on the nature of functional categories and projections. Tese de doutorado. Massachusetts Institute of Technology, 1990.

Neves, Maria Helena de Moura.(2000) Gramática de usos do Português. São Paulo: Editora UNESP.

OPIR (Organização dos Professores Indígenas de Roraima).(2006) Watuminhap wapichan da'y! "Vamos aprender Wapichana". Apostila das lições 1 a 26 do Programa de língua Wapichana para Rádio FM Monte Roraima. Direção: Dr. Ronaldo B. MacDonell. Boa Vista, Roraima.

Pires de Oliveira, Roberta; Giovannetti, Marcelo. Bare nouns and object mass nouns in Wapichana. In. XI Workshop on Formal Linguistics. Universidade Federal do Paraná - Curitiba, PR, 2016.

Santos, Manoel Gomes dos. (2006) Uma gramática do Wapixana (Aruák): aspectos da fonologia, da morfologia e da sintaxe. - Campinas, SP.

Silva, Benedita.; Souza, Nilzimara.; Oliveira, Odamir. et. al. (2013) Paradakary urudnaa: dicionário Wapichana/Português, Português/Wapichana. - Boa Vista: EDUFRR. 